\title{
Design, Modeling and Analysis of a Brushless Doubly-Fed Doubly-Salient Machine for Electric Vehicles
}

\author{
Ying Fan, K. T. Chau \\ Department of Electrical \& Electronic Engineering \\ The University of Hong Kong \\ Hong Kong, China \\ yfan@eee.hku.hk, ktchau@eee.hku.hk
}

\begin{abstract}
This paper presents a new three-phase 12/8-pole brushless doubly-fed doubly-salient (BDFDS) machine for application to electric vehicles. The key is to design, modeling, analyze and control the proposed BDFDS machine. The output power equation is analytically derived, and the initial calculation of machine dimensions and parameters are also discussed. By using finite element analysis, the field distributions of the BDFDS machine at different load and field current are obtained, in which the magnetic saturation and the coupling between armature current flux and field current flux are considered; moreover, the static characteristics of the proposed machine are given. Based on the static characteristics, the system mathematical model has been established. Hence, the evaluation of system performances is conducted by computer simulations in which the simulation model combines the machine with a 3-phase half-bridge converter. A 12/8-pole BDFDS machine is designed and built for exemplification, and a drive system employing this new machine has been developed and investigated experimentally. Experimental results are also given to verify the validity of the theoretical analyses.
\end{abstract}

Keywords-Doubly salient motors; brushless machines; electric vehicles.

\section{INTRODUCTION}

With ever increasing concerns on our environment, the development of electric vehicles (EVs) has taken on an accelerated pace. To enable EVs directly competing with gasoline vehicles, our goals of the EV motor drive are to pursue high efficiency over wide speed range, high power density, high controllability, high reliability and maintenancefree operation. The torque speed characteristic of DC motors are attractive for EV propulsion, but owing to the drawbacks of low efficiency, low power density, as well as the need of mechanical commutator and carbon brushes, DC motors are being superseded by induction motors, permanent magnet brushless motors (PMBL) [1]-[2] and switched reluctance motor (SR). Moreover, the doubly salient permanent magnet (DSPM) motor has recently been proposed which combines the advantageous features of both PMBL and SR motor [3]-[7]. Nevertheless, the DSPM motor still suffers from the drawbacks similar to that of the PMBL motor drives, namely the uncontrollable PM flux at high speed operation and high PM cost.

Previous researches in the doubly salient permanent magnet (DSPM) motor drive have suggested that the PM excitation can be directly replaced by a DC field winding. Basing on this idea, the new motor will consist of two types of stator windings which are polyphase armature winding and DC fielding, socalled the brushless doubly-fed doubly-salient (BDFDS) motor drive. Since the DC current flowing through the field winding can be independently controlled, the BDFDS motor drive will not only solve the fundamental problem of the DSPM motor drive, but also offer the possibility to on-line optimize the efficiency.

The purpose of this paper is to design and analysis a threephase 12/8-pole brushless doubly-fed doubly-salient (BDFDS) machine for electric vehicles. Section II will give a brief introduction of the BDFDS machine. The design procedure will be described to decide the initial dimensions and parameters of this machine in Section III. Section IV will be devoted to the electromagnetic analysis and system modeling. The finite element analysis (FEA) is applied to analyze the static characteristics of the machine, in which the magnetic saturation and the coupling between armature current flux and field current flux are considered. In Section V, the simulation which the converter is also included in the whole system will be discussed. The implementation and experimental verification will be given in Section VI. Finally, conclusions will be drawn in Section VII.

\section{MACHINE DESCRIPTION AND OPERATING PRINCIPLES}

Fig. 1(a) depicts a three-phase 12/8-pole BDFDS machine, which consists of two types of stator windings which are DC field winding and three-phase concentrated armature winding. It has the same structure as a SR motor with twelve salient poles in the stator and eight salient poles in the rotor. Since there are no PMs, no brushes and no windings in the rotor, it offers very simple rotor structure and the capability to run at very high speed. Because the DC current flowing through the field winding can be independently controlled, this BDFDS machine will not only solve the fundamental problem of the

This work was supported and funded in part by the Research Grants Council of Hong Kong and the Research and Conference Grants Committee of The University of Hong Kong. 
DSPM motor, but also offer the possibility to on-line optimize the efficiency.

The operating waveforms of field flux linkage $\psi$ and phase current $i_{s}$ with respect to the rotor position $\theta$ are shown in Fig. 1(b). When the rotor pole is entering the zone of a conductive phase, the flux of the phase winding is increasing. By applying positive current to the winding, the positive torque will be produced. When the rotor pole is leaving the stator pole from the aligned position, the flux is decreasing, and a negative current when the PM flux is decreasing. The positive torque is also produced by applying negative current to the winding. Therefore, the two possible torque producing zones are fully utilized.

\section{DESIGN}

Having valuable research experience in the DSPM motor [3], the output power $P_{o}$ equation of the BDFDS machine can be deduced as:

$$
P_{o}=\frac{0.87 \pi^{2}}{120} \frac{N_{r}}{N_{s}} k_{d} k_{e} k_{i} A_{s} B_{\delta} n_{s} \eta D_{i s}^{2} l_{e f}
$$

where $P_{o}$ is the output power, $N_{s}$ and $N_{r}$ are the stator and rotor pole numbers, respectively, $k_{d}$ is the flux leakage factor, $k_{e}=U / E$ is the ratio of voltage to back EMF; Generally, the ranges of $k_{d}$ and $k_{e}$ are presented as:

$$
\left\{\begin{array}{l}
k_{d}=0.9 \sim 0.93 \\
k_{e}=1.5 \sim 2.0
\end{array}\right.
$$

$k_{i}$ is the ratio of current amplitude $I_{m}$ to rms value of current $I_{r m s}$, it can be computed as:

$$
I_{r m s}=\sqrt{\frac{1}{T} \int_{0}^{T} i^{2} d t}=\sqrt{\frac{1}{\theta_{c r}} 2 I_{m}^{2} \theta_{w}}=\sqrt{\frac{2}{3} I_{m}^{2}}=\sqrt{\frac{2}{3}} I_{m}
$$

where $T$ is the running cycle, $i$ is the instantaneous phase current. In (3), $\theta_{w} / \theta_{c r}=1 / 3$ is based on the operating principle shown as Fig. 1(b). Thus

$$
k_{i}=\frac{I_{m}}{I_{r m s}}=\sqrt{\frac{3}{2}}
$$

$A_{s}$ is the electric loading of stator, it can be chosen in the range of $100 \sim 300 \mathrm{~A} / \mathrm{cm} ; B_{\delta}$ is the air-gap flux density, it is usually selected $1.5 \mathrm{~T} ; n_{s}$ is the rated speed in $1500 \mathrm{rpm}, \eta$ is the machine efficiency in $82 \%, D_{i s}$ is the inner diameter of stator, $l_{e f}$ is the effective stack length.

There is a wide range of possible combinations of phase windings, stator and rotor pole numbers that can be chosen for a BDFDS machine design. In accordance with the basic operation principle of the BDFDS machine, the general relationships among stator pole number $N_{s}$, rotor pole number $N_{r}$ and phase number $m$ are given by:

$$
\left\{\begin{array}{l}
N_{s}=2 m k \\
N_{r}=N_{s} \pm 2 k
\end{array}\right.
$$

where $k$ is a positive integer. When the machine runs at the speed of $n$, the commutating frequency of any phase is $f_{p h}=N_{r} n / 60$. To minimize the switching frequency and hence the loss in power switches as well as the iron losses in poles and yokes, the number of rotor poles should be selected as small as possible. Therefore, the number of rotor poles is usually less than that of stator poles. To make the motor capable of starting itself in either forward or reverse direction, the phase number should be equal to or greater than three. Thus, $N_{s} / N_{r}=6 / 4,8 / 6$ and $12 / 8$ are possible configurations of the BDFDS machine. As compared to the three-phase 6/4pole one, the three-phase 12/8-pole BDFDS machine possesses shorter flux paths in yoke resulting in less magnetic potential drop and iron losses. Moreover, because the flux per magnetic pole is halved in 12/8-pole machine, the width of both stator yoke and teeth is almost one-half of those of a 6/4-

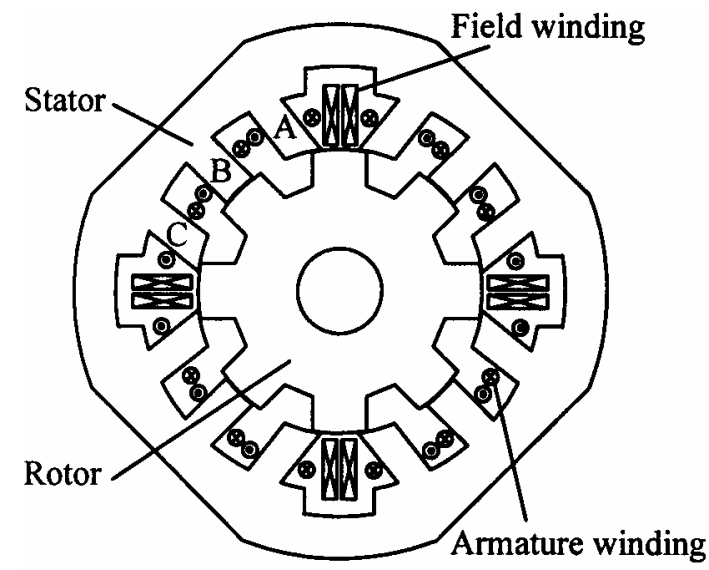

(a)

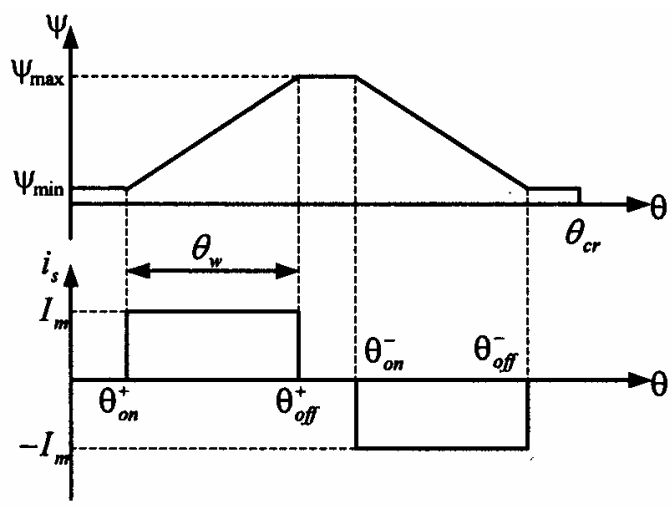

(b)

Figure 1. Three-phase 12/8-pole BDFDS machine. (a) Configuration.(b) Operating principle. 
pole machine. This allows greater inner stator diameter and hence greater rotor diameter. Therefore, higher torque density can be achieved. Furthermore, less width of stator teeth results in shorter end part of phase windings, leading to less copper consumption and resistance of windings. Hence, higher efficiency can be expected for the BDFDS machine.

\section{Finite ElEMENT ANALYSIS AND SyStem MATHEMATICAL MODEL}

\section{A. Finite Element Analysis}

By using the finite element method (FEM), the static characteristics of the BDFDS machine are analyzed. For simplicity, the two-dimensional (2D) FEM is adopted to determine the magnetic field distribution of the BDFDS machine.

Due to the periodic machine configuration, the region of interests for finite element analysis is a half of the whole machine cross-section. The magnetic field distributions of the proposed BDFDS machine at different rotor position and load are analyzed, Fig. 2(a) shows the field produced by field current only and Fig. 2(b) shows the field produced by armature current of phase B only. It can be found that the flux path is concentrated on the overlapping area between the stator and rotor teeth. Based on the FEA results, the characteristics of the BDFDS machine, including the field flux linkage, selfinductance, mutual inductance, back EMF can be obtained. The flux linkage which varies with the rotor angle and the field current is shown in the Fig. 3. Moreover, the simulated inductance characteristics are obtained as shown in Fig. 4.

\section{B. System Mathematical Model}

The system matrix equations describing the three-phase 12/8-pole BDFDS machine is expressed as:

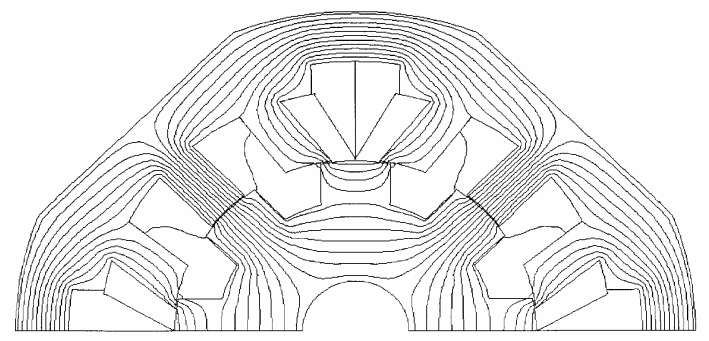

(a)

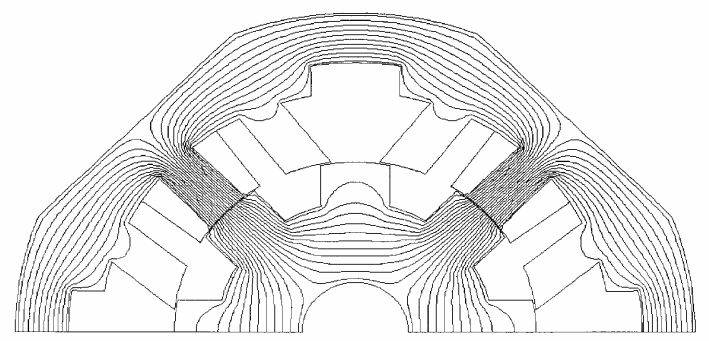

(b)

Figure 2. Simulated magnetic field distributions using FEM. (a) No-load. (b) Armature current only.

$$
\bar{U}=\bar{R} \bar{I}+d \bar{\Psi} / d t
$$

where $\bar{U}=\left[u_{a}, u_{b}, u_{c}, u_{f}\right]^{T}$ is the matrix of the applied voltages, $u_{a}, u_{b}, u_{c}$ are the phase voltages and $u_{f}$ is the field voltage. $\bar{I}=\left[i_{a}, i_{b}, i_{c}, i_{f}\right]^{T}$ is the matrix of applied currents. $i_{a}, i_{b}, i_{c}$ are the phase currents and $i_{f}$ is the field current, $\bar{R}=\operatorname{diag}\left[r_{a}, r_{b}, r_{c}, r_{f}\right]$ is the matrix of resistances, $r_{a}, r_{b}, r_{c}$ are the armature winding resistances and $r_{f}$ is the field winding resistance, the matrix of inductances is given as:

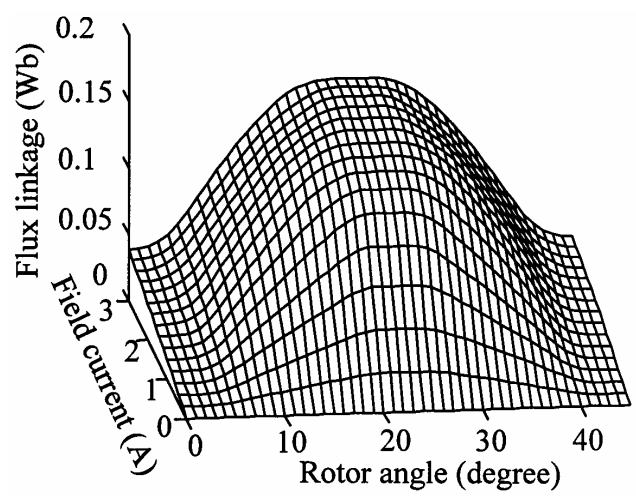

Figure 3. Simulated flux linkage using FEM.

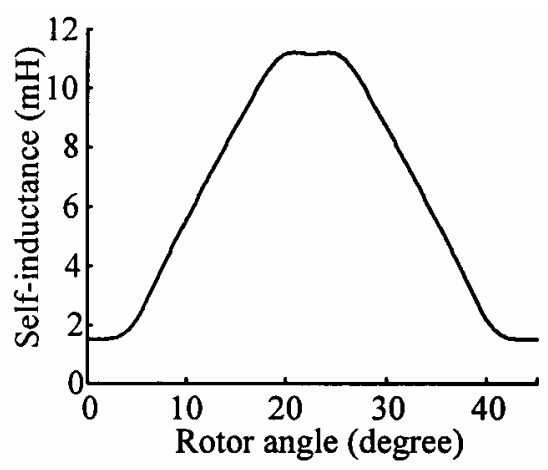

(a)

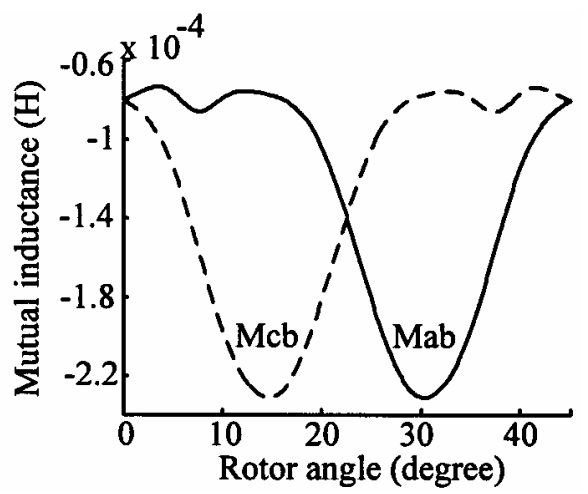

(b)

Figure 4. Inductance characteristics using FEM. (a) Self-inductance. (b) Mutual inductance. 


$$
\bar{L}=\left[\begin{array}{cccc}
L_{a a} & M_{a b} & M_{a c} & M_{a f} \\
M_{b a} & L_{b b} & M_{b c} & M_{b f} \\
M_{c a} & M_{c b} & L_{c c} & M_{c f} \\
M_{f a} & M_{f b} & M_{f c} & L_{f f}
\end{array}\right]
$$

where $L_{a a}, L_{b b}, L_{c c}$ are the self-inductances of armature winding and $L_{f f}$ is the self-inductances of field winding. $M_{a b}, M_{b a}, M_{a c}, M_{c a}, M_{b c}, M_{c b}$ are the mutual inductances between the armature windings, $M_{a f}, M_{f a}, M_{b f}, M_{f b}, M_{c f}, M_{f c}$ are the mutual inductances between the armature windings and field winding. $\bar{\Psi}=\bar{L} \bar{I}$ is the matrix of flux linkages, respectively. Therefore,

$$
d \bar{\Psi} / d t=\bar{L}(d \bar{I} / d t)+(d \bar{L} / d t) \bar{I} .
$$

Thus, the system equation (6) can be rewritten as:

$$
\frac{d \bar{I}}{d t}=\bar{L}^{-1} \bar{U}-\bar{L}^{-1}\left(\bar{R}+\frac{d \bar{L}}{d \theta} \omega_{r}\right) \bar{I}
$$

where the $\omega_{r}$ is the rotor mechanical speed, $\theta$ is the rotor position which is a mechanical angle. The energy stored in the magnetic field under current $\bar{I}$ can be expressed as $W_{f}=\bar{I}^{T} \bar{L} \bar{I} / 2$. When the iron loss is neglected, the input power of the machine can be described as:

$$
\begin{aligned}
\bar{I}^{T} \bar{U} & =\bar{I}^{T} \bar{R} \bar{I}+\bar{I}^{T} \bar{L} \frac{d \bar{I}}{d t}+\bar{I}^{T} \frac{d \bar{L}}{d t} \bar{I} \\
& =\bar{I}^{T} \bar{R} \bar{I}+\frac{1}{2} \bar{I}^{T} \frac{d \bar{L}}{d t} \bar{I}+\frac{d}{d t}\left(\frac{1}{2} \bar{I}^{T} \bar{L} \bar{I}\right) \\
& =\bar{I}^{T} \bar{R} \bar{I}+\frac{1}{2} \bar{I}^{T} \frac{d \bar{L}}{d \theta} \bar{I} \omega_{r}+\frac{d}{d t}\left(\frac{1}{2} \bar{I}^{T} \bar{L} \bar{I}\right)
\end{aligned}
$$

Equation (10) can be rewritten as $P_{i n}=P_{c u}+T \omega_{r}+d W_{f} / d t$. Therefore, the torque can be calculated by:

$$
T=\frac{1}{2} \bar{I}^{T} \frac{d \bar{L}}{d \theta} \bar{I}
$$

\section{Simulation Results}

\section{A. Converter Configuration and control strategy}

To supply the BDFDS machine, a bipolar converter topology is preferred so as to make bi-directional current operation possible. Thus, there are two converter topologies in which the phase current can be controlled individually for bidirectional operation, namely the full-bridge converter and the half-bridge converter with split capacitors. The half-bridge converter is adopted as shown in Fig. 5, because it minimizes the number of power devices and each phase current can be independently controlled. The connection between the midpoint of the split capacitors and the neutral of motor windings, as shown by the dotted line in Fig. 5, is usually necessary to accommodate the additional current during the commutation period.
In order to produce maximum output and increase the system efficiency, the turn on angle is specially chosen to assure that the phase current is the maximum at the point when the phase flux linkage starts to increase. The turn off angle is selected to get the maximum viable torque. According to the flux linkage profiles of each phase shown as the upper traces $\left(\psi_{a}, \psi_{b}, \psi_{c}\right)$ in Fig. 6, the control logic for each switch in the converter is portrayed as the lower traces ( $\left.S_{1}, S_{2}, S_{3}, S_{4}, S_{5}, S_{6}\right)$ in Fig. 6. At any instant in time two phases are energized and one phase is off. The command currents in each phase are described as Fig. 7, in which $\theta_{e}$ is the electrical angle and the relation between the electrical angle and mechanical angle is $\theta_{e}=N_{r} \theta$.

Two operating modes are simulated. One is the low speed operation which the hysteresis current control is used for constant torque operation and the other is the high speed operation which the single pulse control strategy is performed for the constant power operation.

\section{B. Simulation Results}

Based on the static characteristics, such as self-inductances, mutual inductances and flux linkages shown in Fig. 3 and Fig. 4, obtained from FEA, the motor performances are simulated using Matlab/Simulink. The use of Matlab/Simulink environment takes advantages of easy programming, high flexibility and plentiful toolboxes. The corresponding power system block is used to simulate the inverter and BDFDS machine together.

In simulation, the currents are solved by (9) after the voltages are determined by the rotor position and switching mode. The instantaneous torque can be calculated by (11) when the currents have been worked out. The control strategy for three-phase BDFDS machine is based on the above analysis, while the torque control is achieved by changing the current reference. The corresponding control logic of those power switches is based on the encoder feedback signals which reflect the rotor position.

The waveforms of total average torque $T_{a v}$, the instantaneous torque $T_{\text {inst }}$, the phase current $i_{a}$, and the flux $\phi_{a}$ under steady state are simulated. Fig. 8 shows these waveforms which the BDFDS machine is operated under the rated load of $4.70 \mathrm{Nm}$ at speed of $600 \mathrm{rpm}$, it can be found the $T_{a v}$ keeps constant and the current amplitude is effectively controlled. Fig. 9 shows these waveforms at high speed of $1800 \mathrm{rpm}$, it can be seen the $T_{a v}$ reduced to realize the constant power operation. The simulated no-load EMF waveform at rated speed is shown in Fig. 10.

\section{IMPLEMENTATION AND EXPERIMENTAL VERIFICATION}

For verification, a 12/8-pole BDFDS machine prototype as shown in Fig. 11, with the ratings of $750 \mathrm{~W}$ and $1500 \mathrm{rpm}$, is designed and built for verification. A drive system employing 
this new motor has been built and investigated experimentally in the electric drive lab of The University of Hong Kong. The experimental set-up and its subsystems are shown in Fig. 18 and Fig. 19.

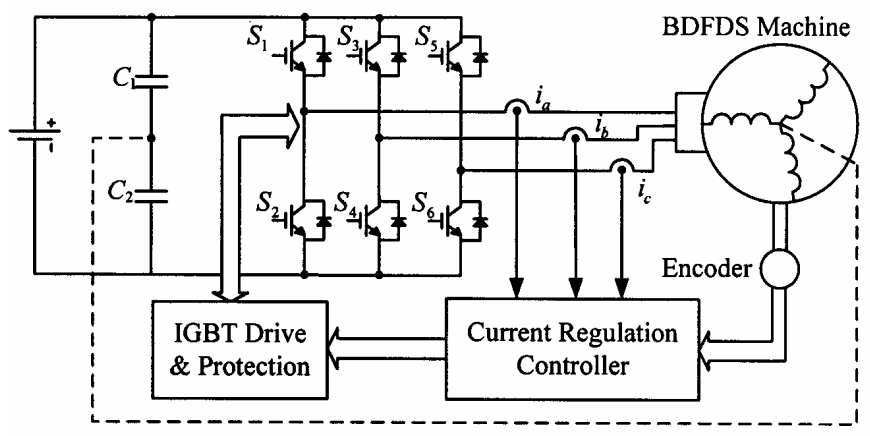

Figure 5. System configuration of the BDFDS machine.

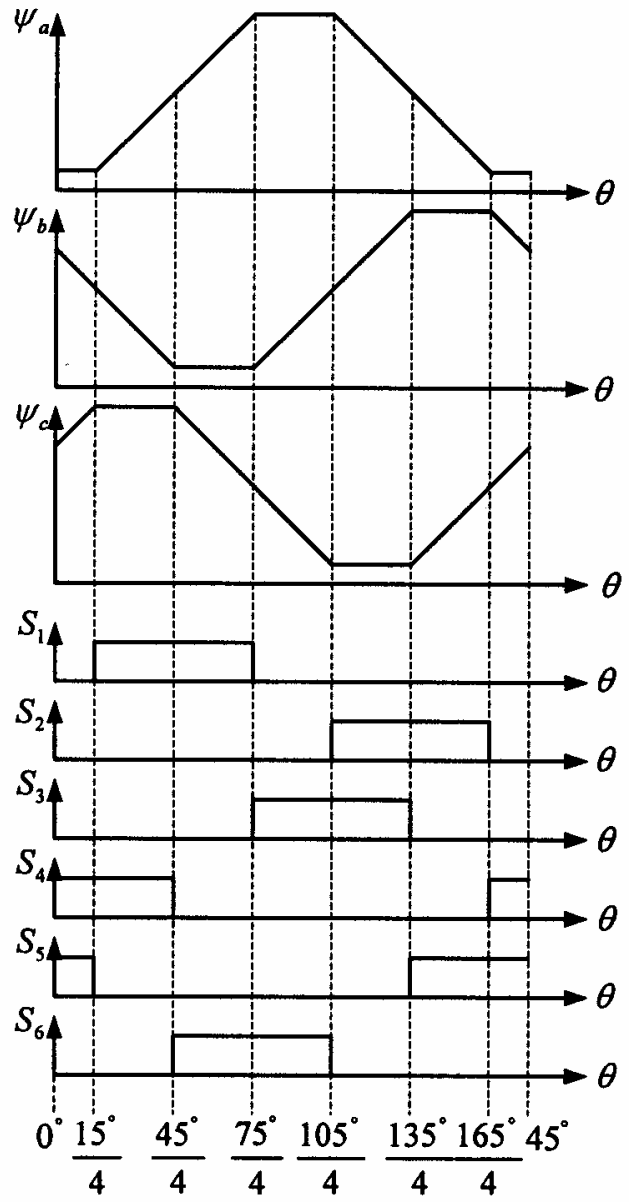

Figure 6. Flux linkages of three-phase windings and control logic of the switches in the half-bridge converter.

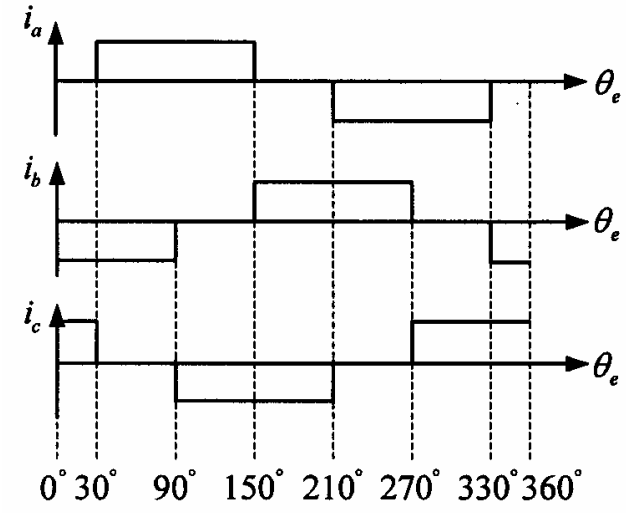

Figure 7. Three-phase command currents.
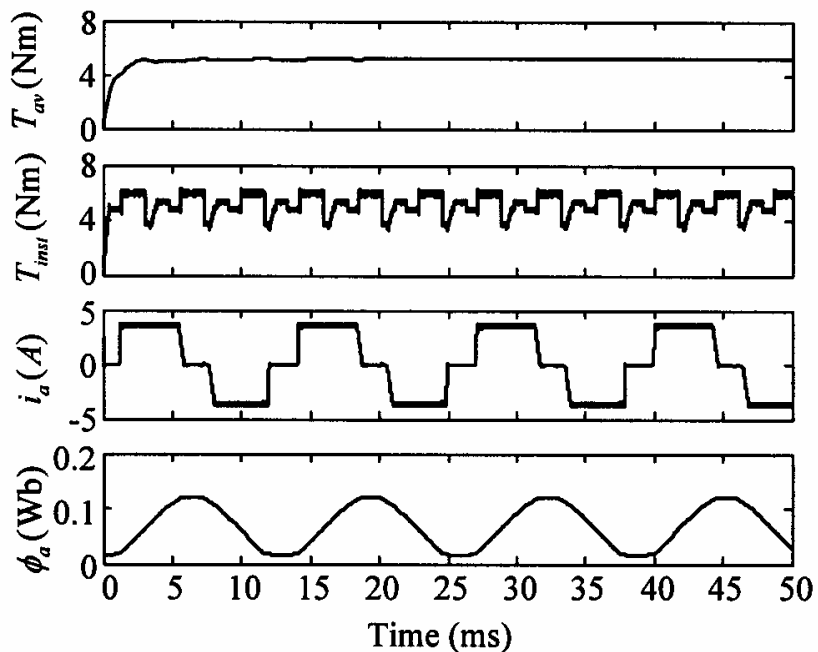

Figure 8. Simulation results of the BDFDS machine under rated load at 600 rpm
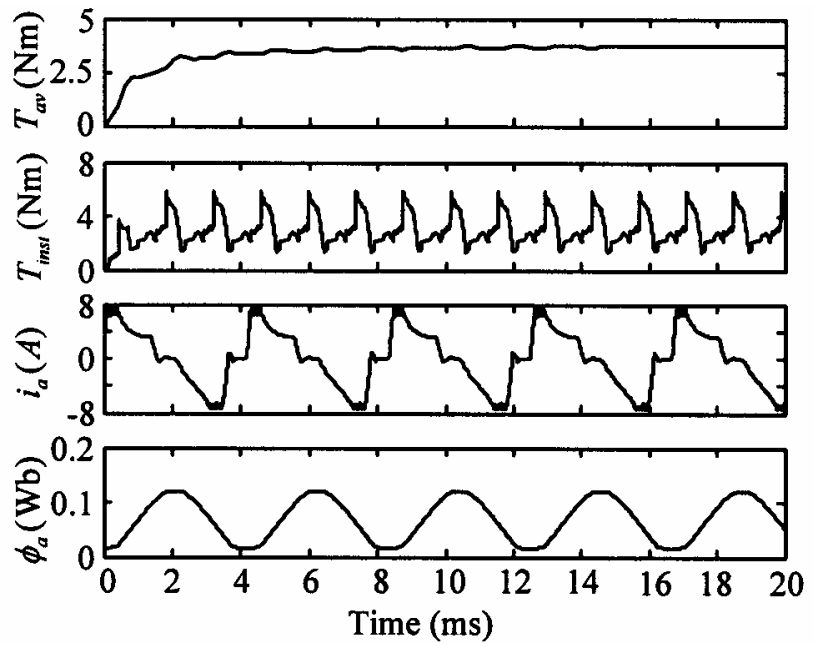

Figure 9. Simulation results of the BDFDS machine at the speed of 1800 rpm. 


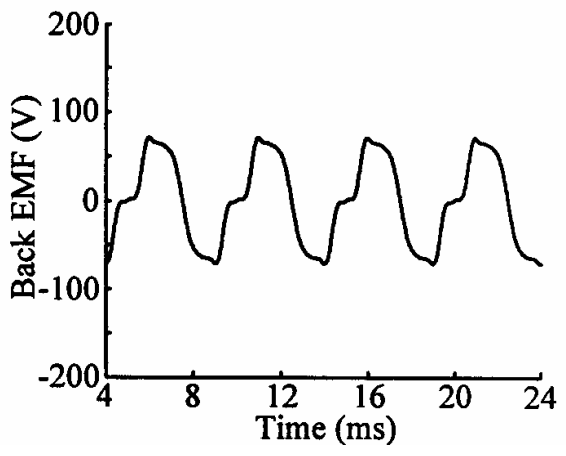

Figure 10. Simulated no-load EMF waveform at rated speed.

\section{A. Description of the Drive System}

Motor: The corresponding key data of the motor are listed in Table I.

Converter and Controller: To verify the performance of the motor, the hystersis current control circuit and three-phase half-bridge converter shown in Fig. 5 was built and used in the experiment drive. The IGBT modules are used as switching devices in the converter.

In accordance with the operation principle of the BDFDS machine, the phase winding should be turned on or off at the specific rotor positions. Hence, the rotor position information is indispensable for the proper operation of the BDFDS machine. For the machine drive system developed in this paper, positions are measured by an optical encoder which produce 10000 pulses per revolution and mounted with the machine in the coaxial way by a coupler as shown in the right part of Fig. 11.

The current is regulated by hysteresis control at low speed and by single pulse control at high speeds. To implement the current control, a controller based on dSPACE DS1104 R\&D controller board was built. The input commands to the controller are the phase current limit, turn on angle, and turn off angle and the feedback signals are rotor position and phase currents. The phase currents are measured by a LEM hall effect current sensor LA25-NP, it measures bi-directional currents up to $25 \mathrm{~A}$ rms from DC to $150 \mathrm{kHz}$, furthermore, it can be mounted on the circuit board and the current ranges can be selected. Based on the control commands and the feedback current and rotor position, the controller produces the driving signals which are transmitted to the gate drivers of the converter.

Load: The load of the tested machine is provided by a DC dynamometer. The operating point of the tested BDFDS machine can be changed by regulating the field current and the electric load - PLZ1003WH of the DC dynamometer.

\section{B. Experimental Results}

Fig. 12 shows the measured no-load EMF waveform at $1500 \mathrm{rpm}$, it can be found that they closely agree with the simulated waveform shown in Fig. 10.

Under the rated load of $4.70 \mathrm{Nm}$ and at the speed of 600 $\mathrm{rpm}$, the phase current, phase voltage and line to line voltages are measured. Fig. 13 shows the measured phase current and phase voltage of the hysterisis control operation, respectively. The line to line voltage between two phases is shown in Fig. 14. Furthermore, both the phase current and total torque are measured at the same condition, the torque is tested by a torque sensor T34FN under steady state, Fig. 15 shows these waveforms. Also, it can be calculated from Fig. 15 that the torque ripple obtained from the measured torque waveforms is about $6 \%$, it is very small, because in the steady state at low speed, the current amplitude is controlled to keep constant.

The phase current and the related gating signals of switches are also measured and as Fig.16 and Fig.17 shown. It is obvious that the measured current waveforms shown in Fig. 13 and Fig. $15 \sim$ Fig. 17 closely agree with the simulated current waveforms shown in Fig. 8, and it can also be found that the new machine has better turn on and turn off performances as predicted by the simulation.

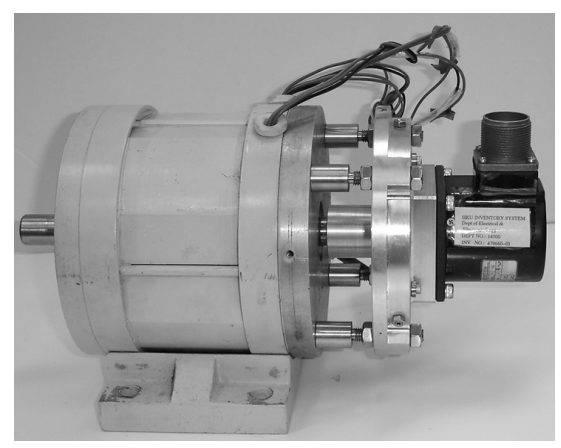

Figure 11. The prototype of BDFDS machine.

TABLE I Specifications of the 12/8-pole BDFDS machine

\begin{tabular}{ll}
\hline Rated speed & $1500 \mathrm{rpm}$ \\
Rated power & $750 \mathrm{~W}$ \\
Rated torque & $4.70 \mathrm{Nm}$ \\
Rated phase voltage & $95 \mathrm{~V}$ \\
Stator inner diameter & $75 \mathrm{~mm}$ \\
Stator outer diameter & $140 \mathrm{~mm}$ \\
Stack length & $75 \mathrm{~mm}$ \\
Air-gap length & $0.30 \mathrm{~mm}$ \\
Stator pole arc & $15^{\circ}$ \\
Rotor pole arc & $22^{\circ}$ \\
Stator pole number & 12 \\
Rotor pole number & 8 \\
Turn No. of armature winding/phase & 120 \\
Turn No. of field winding & 700 \\
\hline
\end{tabular}




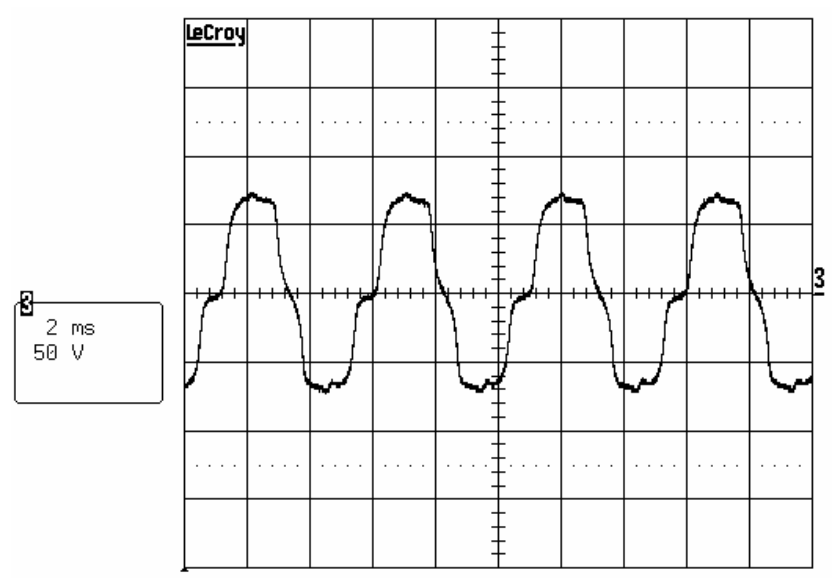

Figure 12. Measured no-load EMF waveform at rated speed (50 V/div, 2 $\mathrm{ms} / \mathrm{div})$.

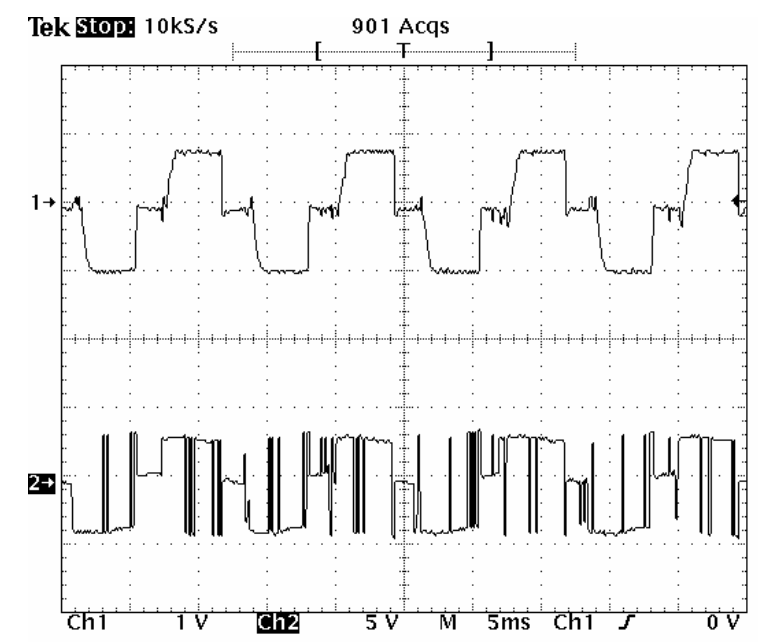

Figure 13. Measured phase current (upper trace)and phase voltage (lower trace) waveforms under rated load (4.5 A/div, $50 \mathrm{~V} / \mathrm{div}, 5 \mathrm{~ms} / \mathrm{div})$.

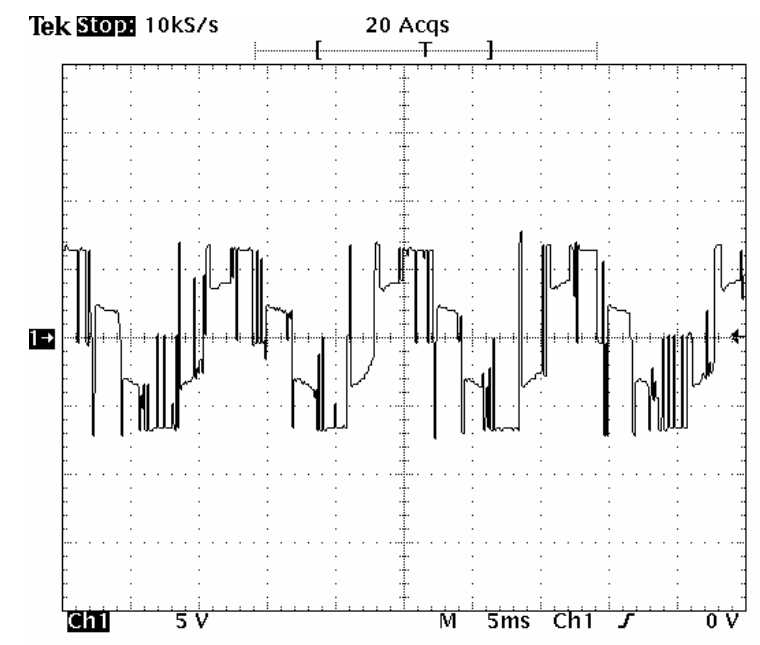

Figure 14. Measured line to line voltage waveform under rated load (50 $\mathrm{V} / \mathrm{div}, 5 \mathrm{~ms} / \mathrm{div})$.

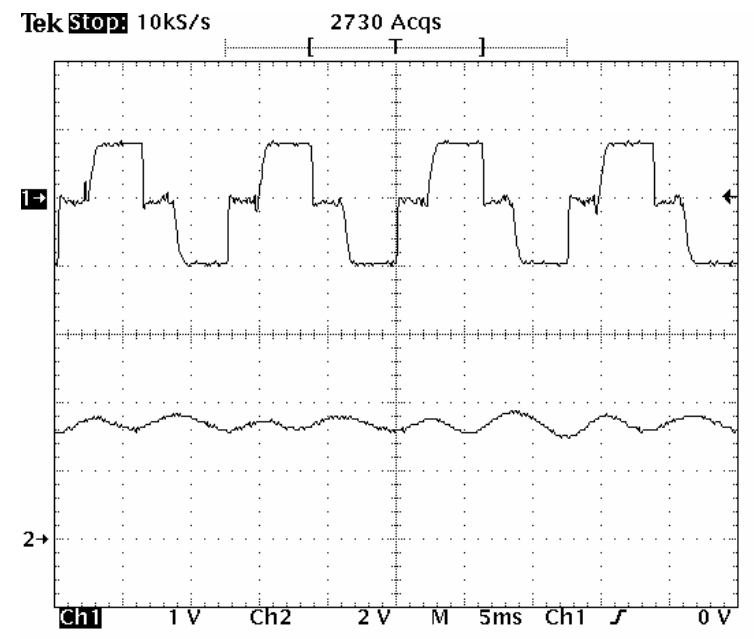

Figure 15. Measured phase current (upper trace) and totoal torque (lower trace) waveforms under rated load (4.5 A/div, $2.8 \mathrm{Nm} / \mathrm{div}, 5 \mathrm{~ms} / \mathrm{div})$.

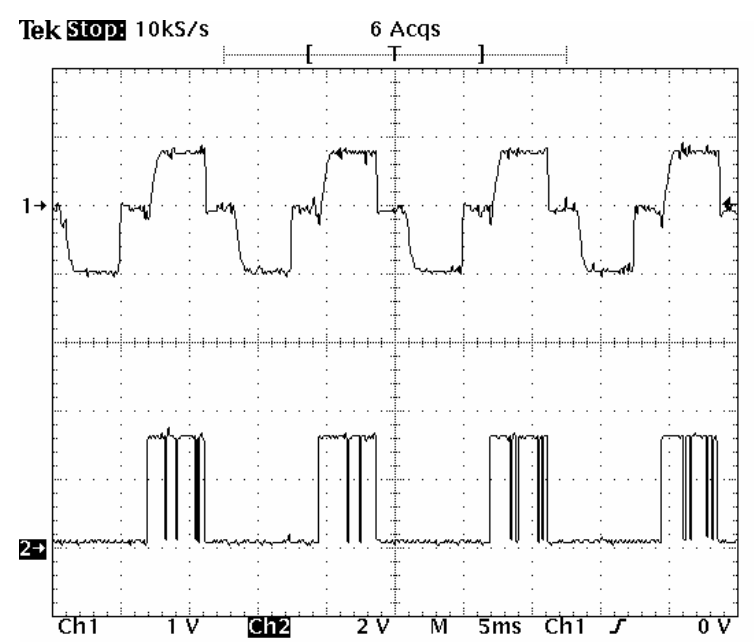

Figure 16. Measured phase current (upper trace) and gating signal of the upper switch (lower trace) waveforms (4.5 A/div, $2 \mathrm{~V} / \mathrm{div}, 5 \mathrm{~ms} / \mathrm{div})$.

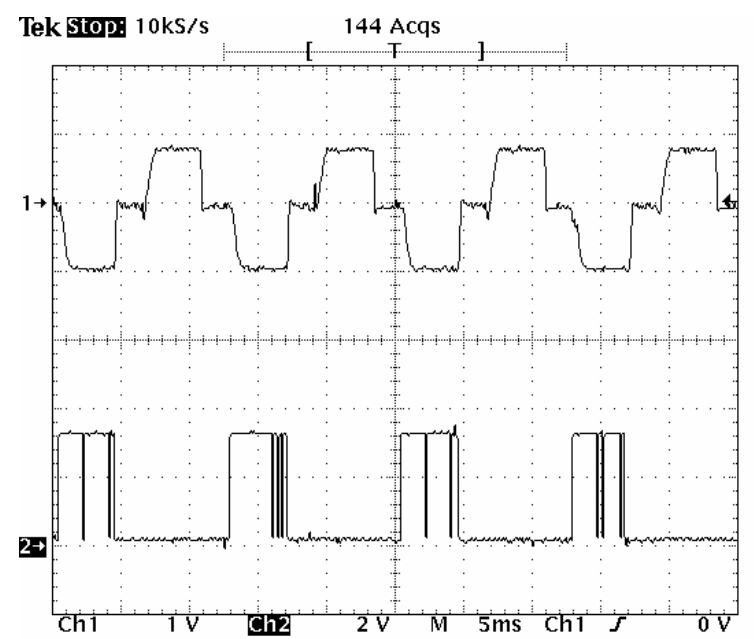

Figure 17. Measured phase current (upper trace) and gating signal of the lower switch (lower trace) waveforms (4.5 A/div, $2 \mathrm{~V} / \mathrm{div}, 5 \mathrm{~ms} / \mathrm{div})$. 


\section{CONCLUSION}

In this paper, the design, modeling, and analysis of a new BDFDS motor has been presented. The output power equation is analytically derived, and the initial calculation of machine dimensions and parameters are also discussed. By using finite element analysis, the field distributions of the BDFDS machine at different load and field current are obtained, in which the magnetic saturation and the coupling between armature current flux and field current flux are considered; moreover, the static characteristics of the proposed machine are given. Based on the static characteristics, the system mathematical model has been established. Hence, the evaluation of system performances is conducted by computer simulations in which the simulation model combines the machine with a three-phase half-bridge converter. Furthermore, a 12/8-pole BDFDS machine is designed and built for verification, a drive system employing this new machine has been developed and investigated experimentally. The experimental results under rated load at low speed have verified the theoretical analyses.

\section{REFERENCES}

[1] P. Zheng; Y. Liu; Y. Wang and S.K. Cheng; "Magnetization analysis of the brushless DC motor used for hybrid electric vehicle," IEEE Transactions on Magnetics, vol. 41, no. 1, 2005, pp. 552-524.

[2] Y.Liu, Z.Q. Zhu and David Howe, "Direct torque control of brushless DC drives with reduced torque ripple," IEEE Transactions on Industry Applications, vol. 41, no. 2, 2005, pp. 599-608.

[3] M. Cheng, K.T. Chau and C.C. Chan, "Design and analysis of a new doubly salient permanent magnet motor," IEEE Transactions on Magnetics, vol. 37, no. 4, 2001, pp. 3012-3020.

[4] R. Deodhar, S. Anderson, I. Boldea and T.J.E. Miller, "The flux-reversal machine: a new brushless doubly-salient permanent magnet machine," IEEE Transactions on Industry Applications, vol. 33, no. 4, 1997, pp. 925-934.

[5] Y.F. Liao, F. Liang and T.A. Lipo, "A novel permanent magnet motor with doubly salient structure," IEEE Transactions on Industry Applications, vol. 31, no. 5, 1995, pp. 1069-1078.

[6] M. Cheng, K.T. Chau, C.C. Chan and Q. Sun, "Control and operation of a new 8/6-pole doubly salient permanent magnet motor drive," IEEE Transactions on Industry Applications, vol. 39, no. 5, 2003, pp. 13631371.

[7] M. Cheng, K. T. Chau and C. C. Chan, "Static characteristics of a new doubly salient permanent magnet motor," IEEE Transactions on Energy Conversion, vol. 16, no. 1, 2001, pp. 20-25.

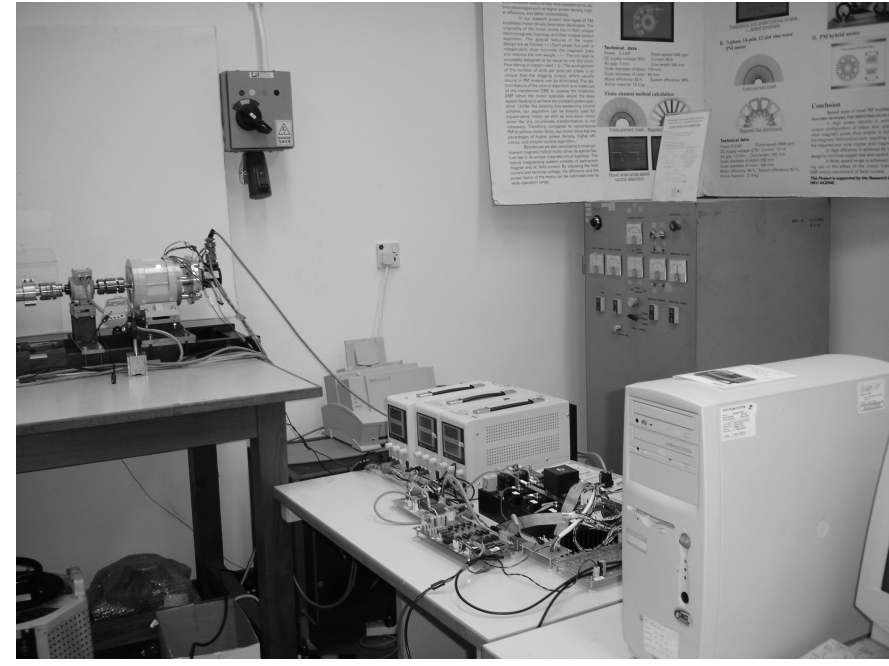

Figure 18. The power converter, gating drive circuit, current sensor, dSPACE connector/led panel and BDFDS machine in the exprimental set-up.

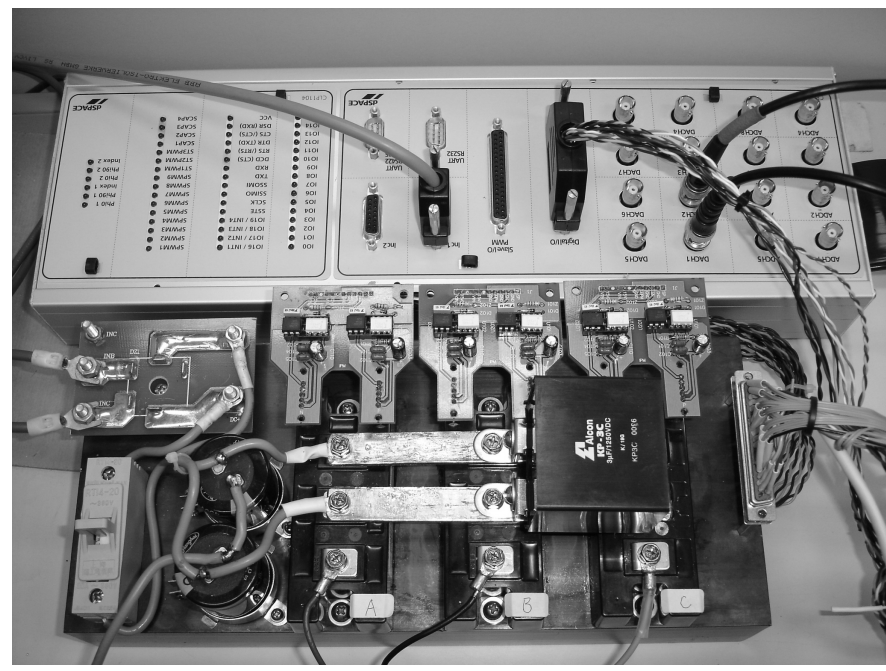

Figure 19. The power converter and dSPACE connector/led panel. 